\title{
ANALISIS PERAWATAN AC (AIR CONDITIONER) UNIT SPLIT DUCT MENGGUNAKAN METODE FAILURE MODE AND EFFECT ANALYSIS FMEA DI HOTEL HARRIS YELLO
}

\author{
Dwi Suryanto \\ Dosen Program Studi Teknik Industri, Faultas Teknik Universitas Pamulang, Banten \\ dosen01309@unpam.ac.id
}

\begin{abstract}
ABSTRAK
Pemeliharan merupkan hal yang penting yang harus dilakukan olehs etiap perusahaan, karen apemelihraan dapatmempengaruhi prose sproduksi yang sedang berjlana adakanya mesin terhenti dikarenakan adanya gangungan yang disebabkan mesin mengalami keruskan pada sala satu komponen, hal ini terjadi biasanya karena mesin kurang atau tidak dijaga maka dari itu perusahaan haru smelakukan pemelihraan yang baik agar tidak terjadi kegagaglan pada mesin, yang menimbulkan juga dalam produktivitas yang menurun. Hal ini juga dialami oleh hotel haris diman pada hotel haris tersedia jumlah aitr condirtioner yang nbanyak jumlahnya, jika ac atau air conditioner tidak dirawata maka besar kemungkinan keandalan pad aac tersebut dapat terganggun diakibatkan daanya ganggunan pada ac yang menyenbabkan konsumen tidak puas akan pelayana yang diberikan oleh hotel haris, kejadiian seperti ini bukan hanya terjadi sekali dua kali tetapi sering nya keajdian kegagalan yang membuat reoutasi perusahaan terganggu, maka dari itu perlu adanya erawatan yang baik pada mesin AC agarar tercapai kondisi yang prima. Salah satu metode yang biasa digunakan dalam merebcanakan perbaikan yaitu metode RCM atau kepanjangan dari reliability centrered maintenance metode ini biasa digunakan dalam merencanakan perawatan mesin yang terpadu. Berdasarkan hasil penelitian Masalah yang paling dominan terjadinya kegagalan atau kerusakan yang sering terjadi adalah komponen Kompresor, Printed Circuit Board (PCB) dan Dinamo Motor Indoor di lihat dari hasil Risk Priority Number (RPN) dengan menggunakan metode Failure Mode And Effect Analsis (FMEA). Kemudian Faktor yang menyebabkan terjadi kegagalan pada komponen kompresor adalah Refrigant berkurang atau adanya kebocoran gas, sehingga kompresor tidak berjalan normal dan bearing yang diatas stationary blade macet terkena partikel karat menimbulkan debu tercampur sehingga kompresor menjadi panas terjadilah kemacetan akibat kurangnya oli dan Refrigant. Adapun Tindakan perbaikan yang harus dilakukan adalah interval waktu penjadwalan berdasarkan metode Reliability Centered Maintenance (RCM), pada bagian komponen Kompresor. Pada bagian ini dengan hasil maksimum dari uji kesesuaian Goodness Of Fit Test distribusi Weibull waktu Maen Time To Repair (MTTR) adalah 99 jam atau 4 hari untuk kegagalan yang tidak dapat diprediksi dengan melakukan upaya tindakan condition monitoring yaitu seperti melakukan pengecekan suhu udara diruang lobby atau remote indoor AC, guna mengurangi terjadinya gangguan-ganguan yang mengurai kualitas kapasitas dan fasilitas Hoter Harris Yello.
\end{abstract}

Kata Kunci : Air conditioener, mesin , FMEA

\section{PENDAHULUAN}

Untuk menunjang kelancaran sekaligus kepuasan pelayanan, maka pelayanan yang terbaik kepada konsumennya. Perusahaan PT Gunung Ansa Retail mempunyai filosofi mengutamakan kualitas layanan yang baik, untuk pelayanan perawatan yang memuaskan serta tepat waktu. Karena permintaan yang semakin pesat dari konsumen maka mulai tahun 2006.

Karena maraknya daya saing dan pesatnya perkembangan teknologi produk AC York yang banyak beberapa tipe unit, maka memberikan kemudahan kepada pengguna untuk kesesuaian yg di butuhkan. Kualitas yang kami jaga memberi jaminan kepada pelayan baik itu produk maupun bagi para pengguna dalam ramah lingkungan. Namun karena banyaknya tipe kami mengambil analisa perawatan AC unit Split Duct, karena tipe ini banyak sekali di gunakan di perkantoran dan perumahan.

Dipilihnya AC tipe Split Duct sabagai objek penelitian ini mempunyai banyak sekali digunakan pada perumahan atau gedung dan bangunan standar berlantai 3 sampai 5 lantai, karena jangkauan pendinginan lebih luas dan bisa di atur keberapa titik atau ruangan. Dalam pengoprasian AC sering terjadi kegagalan yang 
muncul di waktu start up atau saat para pekerja sedang melakukan aktivitas di ruang lobby.

Selama PT. Gunung Ansa Retail mengoperasikan AC unit Split Duct dari tahun 2016 sampai tahun 2019 di Hotel Harris Yelow daerah hayam muruk. Ketika suatu sistem mengalami kerusakan pada kompresor 55\%, PCB (Printed Circuit Board) 25\% dan Dinamo Moto Indoor $20 \%$ komponen lainnya pada mesin AC diluar jadwal yang seharusnya dikarenakan $\mathrm{AC}$ tipe ini di coba untuk dipasarkan ke proyek bangunan atau perumahan. Dimana jumlah kegagalan tersebut sangat memakan biaya yang tinggi dan sangat menggangu operasional.

Selama 1 tahun ada beberapa kegagalan (failer) saat AC dioperasikan. Dalam bidang perawatan gedung, kegiatan pemeliharaan merupakan ujung tombak dari kesuksesan pelayanan. Kegiatan pemeliharaan ini dimaksudkan untuk menjaga dan mempertahankan kelangsungan operasional dan kinerja sistem AC Split Duct agar berjalan sesuai dengan diharapkan. Maka sistem tersebut memerlukan perawatan perbaikan. Perawatan perbaikan ini menyebabkan biaya Downtime yang mahal dan resiko yang tinggi jika sistem tersebut adalah sistem yang besar dengan unitunit yang mahal harganya. Untuk itu Hotel Harris Yelow harus memerlukan pemeliharaan untuk mencegah sebelum terjadinya kerusakan, maka biaya yang dihasilkan akan lebih kecil dari pada biaya perawatn perbaikan. Hal ini dikarenakan pemeliharaan pencegahan memerlukan waktu uang lebih kecil atau sedikit jika dibandingkan dengan perawatan perbaikan sehingga Uptime yang diharapkan dari sistem juga dapat meningkat. Serta diprioritaskan untuk dilakukan tindakan perbaikan,

\section{DASAR TEORI}

\section{A. Definisi perawatan}

Pengertian

perawatan

maintenance sebagai konsepsi dari semua aktivitas yang diperlukan untuk menjaga atau mempertahankan kualitas fasilitas/mesin agar dapat berfungsi dengan baik seperti kondisi awalnya (Ansori dan Mustajib, 2013). Dari pengertian diatas dapat ditarik beberapa kesimpulan, bahwa:

1. Fungsi perawatan sangat berhubungan erat dengan proses produksi;
2. Aktivitas perawatan banyak berhubungan erat dengan pemakaian peralatan, bahan pekerjaan, cara penanganan dan lain-lain.

Perawatan dilakukan untuk perbaikan yang bersifat kualitas, meningkatkan suatu kondisi lain yang lebih baik. Banyaknya pekerjaan perawatan yang dilakukan tergantung pada:

1. Batas kualitas terendah yang diizinkan dari suatu komponen sedangkan batas kualitas yang lebih tinggi dapat dicapai dari hasil perawatan mesin;

2. Waktu pemakaian mesin yang berlebihan yang dapat menyebabkan berkurangnya kualitas peralatan.

\section{Failure Mode and Effect Analysis (FMEA)}

Failure Mode and Effect Analysis

(FMEA) meupakan suatu teknis analisis yang menggabungkan teknologi dan pengalaman manusia dalam mengidentifikasi ragam kecacatan yang dapat dilihat pada produk atau proses dan membuat perencanaan untuk menghilangkannya. Failure Mode and Effect Analysis (FMEA) adalah salah satu tool paling yang sering digunakan dalam praktek bussines performance improvement, dan merupakan teknik yang pertama diciptakan untuk menganalisa kesalahan (failure) pada proses.

\section{Reliability Centered Maintenance (RCM)}

Reliability Centered Maintenance (RCM) merupakan suatu metode perawatan yang memanfaatkan informasi yang berkenaan dengan keandalan suatu fasilitas, untuk memperoleh strategi perawatan yang efektif, efisien dan mudah untuk melaksanakan. Melalui penggunaan RCM, dapat diperoleh informasi apa saja yang harus dilakukan untuk menjamin mesin atau peratan dapat terus beroperasi dangan baik. Selain itu juga ada yang mendefisikan Reliability Centered Maintenance (RCM) adalah suatu metode yang digunakan untuk mengembangkan dan memilih alternative desain pemeliharaan berdasarkan kriteria keselamatan operasional.

Kerangka pikir 


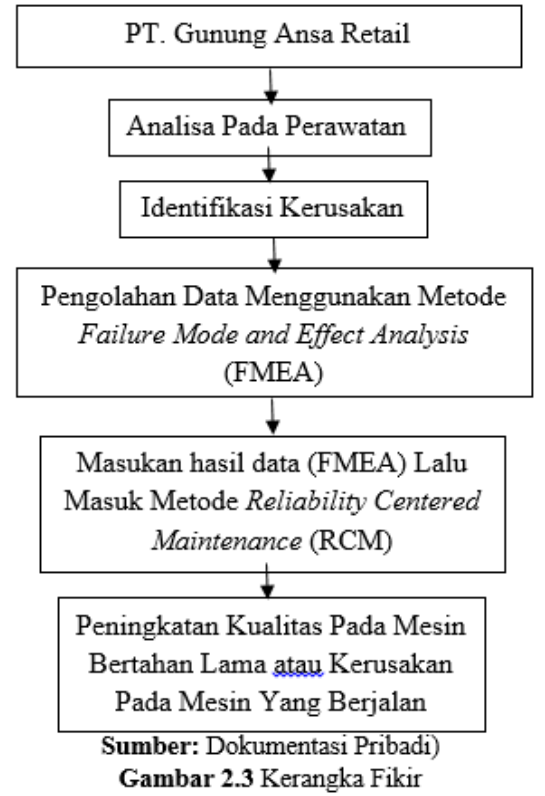

\section{METODE DAN TEKNIK PENGUKURAN}

Dalam rangka memperoleh data-data yang diperlukan maka tentu saja ada beberapa metode atau teknik yang dipergunakan dalam penelitian ini. Hal ini dimaksud agar data-data yang dibutuhkan dapat diperoleh dengan mudah dan seakurat mungkin. Oleh karena itu, dalam pelaksanaan pengumpulan data guna meneliti tentang analisis perawatan pada mesin Air Conditioner Split Duct di Hotel Harris Yello, penulis menggunakan metode Failure Mode and Effect Analysis (FMEA) dan Reliability Centered Maintenance (RCM) dimana metode ini dianggap penulis sangat cocok dalam penelitian mengenai masalah perawatan pada mesin AC. Adapun data dan sumber data yang diperlukan adalah sebagai berikut:

\section{Penelitian Kerja}

Penelitian kerja merupakan cara atau kegiatan pengumpulan data dimana peneliti terjun langsung kelapangan untuk mengadakan penelitian pengamatan. Dalam hal ini, penulis mengamati secara langsung proses dibangun proyek instalasi AC dari proses awal sampai proses akhir dan juga mempelajari faktor apa saja yang berpotensi menimbulkan kerusakan yang akan menjadi bahan penelitian.

\section{Interview}

Dalam hal ini peneliti membuat pertanyaan yang berkaitan dengan penyebab kerusakan pada mesin AC kepada staff kepala teknisi terkait, dan juga karyawan yang bertugas langsung untuk memperbaiki AC yang ada di ruang lokasi tersebut, dimana dari data interview ini akan digunakan sebagai data pendukung.

3. Studi Pustaka

Studi pustaka adalah pengumpulan informasi yang dibutuhkan terkait dengan peenelitian dengan mempelajari berbagai macam material yang ada di perpustakan seperti buku, dokumen, penelitian terdahulu, jurnal dan lain sebagainya.

Teknik pengumpulan data adalah salah satu cara pengadaan data primer maupun data sekunder untuk keperluan penelitian. Secara umum pengumpulan data baik data primer maupun data sekunder dapat dibagi atas beberapa cara yaitu:

1. Data Primer adalah data yang diperoleh dari pengamatan dan penelitian langsung dilapangan. Pengumpulan data primer ini dilakukan dengan cara mengamati secara langsung proses perawatan di ruang lokasi terutama proses kerja yang berpotensi menimbulkan downtime paling tinggi, selain itu data primer didapat juga dengan mewawancarai langung operator dan staff terkait. Data yang diperoleh antara lain berupa factor-factor penyebab terjadinya kerusakan.

2. Data sekunder adalah data yang tidak langsung diamati oleh penulis. Data ini dapat berupa dokumentasi perusahaan, hasil penelitian yang sudah lalu dan data lainnya. Data sekunder ini digunakan untuk melengkapi hasil penelitian yang dilakukan, data sekunder diperoleh dari data perusahaan, yaitu berupa profil perusahaan, SOP, intruksi kerja, data downtime sebelumnya, dan data pendukung lainnya.

\section{Metode Analisa Data}

Untuk memperoleh gambaran yang lebih baik dan pemecahan dari masalah yang dihadapi, maka data-data yang telah diperoleh perlu disusun terlebih dahulu sesuai dengan metode perhitungan yang digunakan, dalam hal data terlebih dahulu dianalisa dan disajikan dengan menggunakan diagram pareto untuk menentukan prioritas masaah yang akan diteliti, kemudian analisis data dilanjutkan metode yang digunakan yaitu dengan menggunakan menggunakan Failure Mode and Effect Analysis (FMEA) dan Reliability Centered Maintenance (RCM). 


\section{HASIL DAN PEMBAHASAN}

Hotel Harris Yello memiliki berbagai fasilitas ramah teknologi untuk memastikan masa menginap yang nyaman di Jakarta. Hotel ini juga sangat bersahabat untuk para pelanggan dan sangta bersahabat dengan teman, klien, atau keluarga. Kualitas hotel ini menggunakan salah satu gadget dan jelajahi web di NetZone dan para kostumer dapat nikmati hidangan lezat di makanan jalanan 24 jam kami yang terinspirasi, Wok'n'Tok Restaurant. Dan banyak lagi fasilitas yang dapat di gunakan untuk aktivitas keseharian seperti Wok dan Tok, Chillspot, Wifi gratis, Ruang rapat, Stasiun Gym, Zona Seni dan Wok-Fast.

Hotel bintang 3 yang trendi di Harmoni, Jakarta Pusat. Hotel Harris Yello Harmoni secara teknis memiliki tempat yang strategis dan dapat dicapai dengan berjalan kaki dari Stasiun Bus Central Harmoni, kurang dari 40 menit dari Bandara Internasional Soekarno Hatta \& Stasiun Kereta Jakarta Kota; 5 menit dari Gajah Mada Plaza, 20 menit dari Monumen Nasional (MONAS) dan 25 menit dari Museum Nasional \& M.H. Distrik bisnis Thamrin.

Hotel Harris Yello didirikan pertengahan tahun 2018 dimana hanya satu-satunya gedung memiliki 3 tempat yaitu penginapan Hotel, pusat belanja dan juga apatermen. Hotel harris sendiri ada di beberapa tempat di jabodetabek dan di beberapa provinsi namun hanya saja gedung sendiri. Pemilik dari Hotel Harris yaitu PT. Agung Podomoro Land.Tbk selalu menjadi disetiap provinsi menjadi kota modern yang tak kalah saing dengaan negara-negara lain. Dimana kedepannya akan menjadi kota-kota modern yang tidak kalah dengan negara barat dimana memberikan kenyamanan bagi masyarakat atau penduduk sendiri dan menjadikan tempat monopoli bisnis untuk penduduknya.

Data yang diperoleh adalah data waktu laporan di Hotel Harris Yello, data historis kerusakan, jam kerja mesin dan data waktu perbaikan, korektif periode Meret 2018 - April 2019 bisa dilihat

\begin{tabular}{|c|c|c|}
\hline $\begin{array}{c}\text { Period } \\
\text { e }\end{array}$ & $\begin{array}{c}\text { lapo } \\
\text { ran }\end{array}$ & Kerusakan Spare Part \\
\hline $\begin{array}{c}\text { Juli } \\
2108\end{array}$ & 7 & $\begin{array}{lccc}1 & \text { Kompresor } \quad 75 \mathrm{pk} & \text { dan } & 2 \\
\text { Kontaktor+Past Protect } & & \end{array}$ \\
\hline $\begin{array}{l}\text { Agust } \\
\text { us } \\
2018\end{array}$ & 6 & 1 Kompresor 10pk \\
\hline $\begin{array}{l}\text { Septe } \\
\text { mber } \\
2018\end{array}$ & 4 & Tidak Ada Pergntian Spare Part \\
\hline $\begin{array}{c}\text { Oktob } \\
\text { er } \\
2018\end{array}$ & 7 & $\begin{array}{l}1 \quad \text { Kompresor, PCB } \text { Indoor } \\
75 \mathrm{pk}+10 \mathrm{pk} \text { dan Remote EWM }\end{array}$ \\
\hline $\begin{array}{l}\text { Nove } \\
\text { mber } \\
2018\end{array}$ & 6 & $\begin{array}{l}1 \text { Motor Indoor, } 1 \text { Kompresor 10pk } \\
\text { dan Remote 13BH }\end{array}$ \\
\hline $\begin{array}{c}\text { Desem } \\
\text { ber } \\
2018\end{array}$ & 8 & $\begin{array}{l}1 \text { PCB Indoor } 75 \mathrm{pk}+10 \mathrm{pk} \text { dan } 2 \\
\text { Filter Dryer }\end{array}$ \\
\hline $\begin{array}{l}\text { Januar } \\
\text { i } 2019\end{array}$ & 7 & $\begin{array}{l}2 \text { Kompresor 10pk dan Comp Loct } \\
\text { Outdoor }\end{array}$ \\
\hline $\begin{array}{l}\text { Februa } \\
\text { ri } 2019\end{array}$ & 6 & $\begin{array}{l}2 \text { Motor Indoor } 75 \mathrm{pk}+10 \mathrm{pk} \text { dan } 1 \\
\text { Kompresor } 75 \mathrm{pk}\end{array}$ \\
\hline $\begin{array}{l}\text { Februa } \\
\text { ri } 2019\end{array}$ & 8 & $\begin{array}{l}1 \text { Fan Bell Indoor, Kompresor } 75 \mathrm{pk} \\
\text { dan Kontraktor Outdoor } 10 \mathrm{pk}\end{array}$ \\
\hline $\begin{array}{l}\text { Maret } \\
2019\end{array}$ & 8 & $\begin{array}{l}1 \text { Filter Driyer, } 1 \text { Motor Indoor } 75 \mathrm{pk} \\
\text { dan Bak Penampung Outdoor }\end{array}$ \\
\hline $\begin{array}{l}\text { April } \\
2019\end{array}$ & 15 & 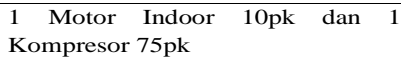 \\
\hline $\begin{array}{c}\text { Mei } \\
2019\end{array}$ & 6 & Tidak Ada Pergntian Spare Part \\
\hline $\begin{array}{l}\text { Juni } \\
2019\end{array}$ & 7 & $\begin{array}{l}\text { 1 PCB Outdoor, Fan Outdoor 10pk } \\
\text { dan } 1 \text { Expansi Outdooor } 75\end{array}$ \\
\hline
\end{tabular}

Data yang diperoleh adalah data waktu laporan di Hotel Harris Yello, data historis kerusakan, jam kerja mesin dan data waktu perbaikan, korektif periode Maret 2018 April 2019. Pada mesin AC Split Duct terdiri dari beberapa komponen, dapat kita ketahui sistem yang menjadi penyebab utama terjadinya Kerusakan pada $A C$ tipe Splite Duct dengan menggunakan diagram pareto dengan mengurutkan peringkat kerusakan sistem dari yang tebesar hingga terkecil seperti

Kerusakan Spare Part dengan mengurutkan peringkat kerusakan sistem terbesar hingga terkecil bisa dilihat pada table 


\begin{tabular}{|c|c|c|c|c|c|c|}
\hline $\begin{array}{c}\text { FAKTOR } \\
\text { KERUSAKAN }\end{array}$ & Code & $\begin{array}{l}\text { Frekuensi } \\
\text { Kerusakan }\end{array}$ & $\begin{array}{l}\text { Frekuensi } \\
\text { Kerusakan } \\
\text { Komulatif }\end{array}$ & $\begin{array}{l}\text { Presentase } \\
\text { Kerusakan }\end{array}$ & $\begin{array}{c}\text { Persen } \\
\%\end{array}$ & $\begin{array}{l}\text { Persen \% } \\
\text { Kumulatif }\end{array}$ \\
\hline $\begin{array}{l}1 \text { Motor Indoor } \\
10 \mathrm{pk} \text { dan } 1 \\
\text { Kompresor } 75 \mathrm{pk}\end{array}$ & A & 15 & 15 & 15 & 14.56 & 14.56 \\
\hline $\begin{array}{c}\text { Tidak Ada } \\
\text { Pergntian Spare } \\
\text { Part } \\
\end{array}$ & B & 10 & 25 & 99 & 9.71 & 24.27 \\
\hline $\begin{array}{c}\text { FAKTOR } \\
\text { KERUSAKAN }\end{array}$ & Code & $\begin{array}{c}\text { Frekuensi } \\
\text { Kerusakan }\end{array}$ & $\begin{array}{l}\text { Frekuensi } \\
\text { Kerusakan } \\
\text { Komulatif } \\
\end{array}$ & $\begin{array}{l}\text { Presentase } \\
\text { Kerusakan }\end{array}$ & $\begin{array}{c}\text { Persen } \\
\%\end{array}$ & $\begin{array}{l}\text { Persen \% } \\
\text { Kumulatif }\end{array}$ \\
\hline $\begin{array}{c}2 \text { Kompresor } \\
75 \mathrm{pk}+10 \mathrm{pk}, 2 \\
\text { Remote, Sensor } \\
\text { udara dan 1 } \\
\text { Kontraktor+Past } \\
\text { Protect } \\
\end{array}$ & C & 8 & 33 & 23 & 7.77 & 32.04 \\
\hline \begin{tabular}{c|}
2 PCB Indoor \\
75pk+10pk dan 2 \\
Filter Dryer \\
\end{tabular} & D & 8 & 41 & 31 & 7.77 & 39.80 \\
\hline $\begin{array}{c}\text { 1 Filter Driyer, } 1 \\
\text { Motor Indoor } 75 \mathrm{pk} \\
\text { dan Bak } \\
\text { Penampung } \\
\text { Outdoor } \\
\end{array}$ & E & 8 & 49 & 39 & 7.77 & 47.57 \\
\hline $\begin{array}{l}1 \text { Fan Bell Indoor, } \\
1 \text { Kompresor } 15 \mathrm{pk} \\
\text { dan Kontraktor } \\
\text { Outdoor 10pk }\end{array}$ & F & 8 & 57 & 47 & 7.77 & 55.34 \\
\hline $\begin{array}{c}2 \text { Kompresor 10pk } \\
\text { dan Comp Loct } \\
\text { Outdoor }\end{array}$ & G & 7 & 64 & 54 & 6.80 & 62.13 \\
\hline \begin{tabular}{|c|} 
1 PCB Outdoor, 1 \\
Fan Outdoor 10pk \\
dan 1 Expansi \\
Outdooor 75 75 \\
\end{tabular} & $\mathrm{H}$ & 7 & 71 & 61 & 6.80 & 68.93 \\
\hline $\begin{array}{l}\text { 1 Kompresor, } 2 \\
\text { PCB Indoor } \\
75 \mathrm{pk}+10 \mathrm{pk} \text { dan } \\
\text { Remote EWM } \\
\end{array}$ & I & 7 & 78 & 68 & 6.80 & 75.73 \\
\hline \begin{tabular}{c|}
1 Kompresor $75 \mathrm{pk}$ \\
dan 2 \\
Kontaktor+Past \\
Protect \\
\end{tabular} & $\mathrm{J}$ & 7 & 85 & 75 & 6.80 & 82.52 \\
\hline $\begin{array}{c}2 \text { Motor Indoor } \\
75 \mathrm{pk}+10 \mathrm{pk} \text { dan } 1 \\
\text { Kompresor } 75 \mathrm{pk}\end{array}$ & K & 6 & 91 & 81 & 5.83 & 88.35 \\
\hline
\end{tabular}

Berdasarkan Tabel diperoleh hasil sebagai berikut:

$\mathrm{M}=\frac{k 1 \sum_{i=k 1+1}^{r-1}[(\ln t i-1-\ln t i) / M i]}{\left.k 1 \sum_{i=1}^{k 1}[\ln t i-1-\ln t i) / M i\right]}$

Dimana: $\mathrm{ti}=\mathrm{xi}=592$

$$
\mathrm{Mi}=74.8241
$$

$\mathrm{r}=$ Jumlah Pengamatan $=14$

$\mathrm{k} 1=\left[\frac{r}{2}\right]=\frac{14}{2}=7$

$\mathrm{k} 2=\left[\frac{r-1}{2}\right]=\frac{14-1}{2}=\frac{13}{2}=6,5=7$

$\mathrm{M}=\frac{k 1 \sum_{8}^{13}(\ln 592-1-\ln 592) / 74.8241}{k 1 \sum_{1}^{7}(\ln 592-1-\ln 592) / 74.8241}$

$\mathrm{M}=\frac{7 \sum_{8}^{13}(6.383-1-6.383) / 74.8241}{7 \sum_{1}^{7}(6.383-1-6.383) / 74.8241}$

$\mathrm{M}=\frac{7 \sum_{8}^{13}(-7)}{7 \sum_{1}^{7}(-7)} \frac{/ 74.8241}{/ 74.8241}=\frac{0.6548}{0.6548}=1$

Menentukan daerah kritis dengan $\alpha=0.01$ dari hasil pengolahan data tabel $\mathrm{F}(0.01 .2 \mathrm{~K} 2.2 \mathrm{~K} 1)=$ $\mathrm{F}(0.01 .14 .14)=1.94$

Kesimpulan: Karena nilai $\mathrm{M}=1<$ $\mathrm{F}(0.01 .14 .14)=1.96$; maka $\mathrm{H} 0$ diterima artinya waktu reparasi mesin AC Split Duct adalah distribusi Weibull.

Adapun langkah-langkah perhitungan table diatas adalah sebagai berikut:

Plot Weibull memberikan metode informasi mengevaluasi ketetapan penggunaan distribusi yang digunakan dan untuk menentukan parameter bagi distribusi yang digunakan, akan menghasilkan nilai yang lebih akurat karena tingkat subjektivitas untuk menilai kelurusan garis menjadi kurang, dengan rumus:

$$
\hat{\mathrm{F}}(\mathrm{ti})=\left(\frac{1-0.3}{n+0.4}\right)
$$

Dimana: $\mathrm{F}(\mathrm{ti})=$ Plot Weibull

$\mathrm{i}=$ Period ke-i

$\mathrm{n}=$ Jumlah Pengamatan

Pendekatan pertama pada plot ini yaitu penentukan persamaan garis $\mathrm{Y}=\mathrm{a}+\mathrm{bx}$. Apabila waktu kerusakan dan waktu reperasi sesuai dengan asumsi dari distribusi, dengan rumus:

$$
\begin{aligned}
& \mathrm{xi}=\ln \mathrm{i}\left[\left(\ln \left(\frac{1}{1-F(t i)}\right)\right)\right] \quad \text { yi }= \\
& {\left[\ln \left(\ln \left(\frac{1}{1-F(t i)}\right)\right)\right]} \\
& \beta=\mathrm{b}=\frac{n * \sum x i y i-\sum x i * \sum y i}{n * \sum x i^{2}-\left(\sum x i\right)^{2}}= \\
& \frac{14(-11.516)-(47.72925)(-7.485)}{14(174.919)-(47.72925)} \\
& =\frac{196.029}{2,401.136}=0.08 \\
& \alpha=\mathrm{a}=\frac{\sum y i-b * \sum x i \sum y i}{n}= \\
& \frac{-7.485-0.08 x(47.72925)(-7.485)}{14}=\frac{21.095}{14}=1.50 \\
& \theta=e^{a . \beta}=e^{1.50 \times 0.08}=e^{0.12}=1.12 \\
& \mathrm{MTTF}=\operatorname{\theta r}\left(1+\frac{1}{\beta}\right)=1.12 \mathrm{r}\left(1+\frac{1}{0.08}\right)=1.12 \\
& \mathrm{r}=(1.35) \\
& =1.12(89115)=99 \mathrm{Jam}=4 \text { hari } 3 \mathrm{jam} \\
& \text { Dimana } r=\text { Tabel Gama }
\end{aligned}
$$

Berikut kesimpulan perhitungan hasil Maximum Like Estimator (MLE) distribusi yang merupakan hasil dari Goodness Of Fit untuk selang waktu kegagalan dan selang waktu perbaikan, hasil dari perhitungan Maximum Like Estimator (MLE)

Dari semua perhitungan dengan menggunakan tabel Failure Mode and Effect Analysis (FMEA) untuk menentukan komponen kritis dari mesin AC Split Duct terdapat komponen yang mudah terjadi kerusakan pada saat oprasional sedang berjalan yaitu pada kompresor, serta pada perhitungan rank atau nilai pada Risk Priority Number (RPN) dengan memiliki rank sebesar 42 (RPN), dikarenakan penyebab yang sering terjadi adalah. Perawatan yang tidak SOP, sering terjadinya mengalami breakdown atau mati secara mendadak. Berdasarkan penjelasan sebelumnya pada uraian-uraian bagian kerusakan komponen, dari presentase kerusakan komponen menunjukan yang terendah dan yang terbesar pada bagian Pada 
bagian komponen ini maka ditetapkan sebagai komponen kritis karena memiliki presentase downtime terbesar yaitu $55 \%$, dibandingkan dengan bagian komponen lainya. Pada komponen kompresor ini dengan hasil peritungan yang sudah ditetapkan untuk catatan interval waktu perawatan selama 99 jam atau 4 hari kerja setidaknya membutuhkan adanya untuk melakukan Condition Monitoring dengan bertujuan untuk mencegah terjadinya kerusakan maupun mengurangi gangguangangguan menghambat selama saat operasional sedang berjalan. Untuk terjadinya kegagalan yang tidak dapat diprediksi maka perlu dilakukan dengan Corrective Maintenance untuk sebelum pemakaian.

\section{KESIMPULAN}

Berdasarkan hasil dari penelitian di Hotel Harris Yello dapat disimpulkan sebagai berikut:

1. Masalah yang paling dominan terjadinya kegagalan atau kerusakan yang sering terjadi adalah komponen Kompresor, Printed Circuit Board (PCB) dan Dinamo Motor Indoor di lihat dari hasil Risk Priority Number (RPN) dengan menggunakan metode Failure Mode And Effect Analsis (FMEA).

2. Faktor yang menyebabkan terjadi kegagalan pada komponen kompresor adalah Refrigant berkurang atau adanya kebocoran gas, sehingga kompresor tidak berjalan normal dan bearing yang diatas stationary blade macet terkena partikel karat menimbulkan debu tercampur sehingga kompresor menjadi panas terjadilah kemacetan akibat kurangnya oli dan Refrigant.

3. Tindakan perbaikan yang harus dilakukan adalah interval waktu penjadwalan berdasarkan metode Reliability Centered Maintenance (RCM), pada bagian komponen Kompresor. Pada bagian ini dengan hasil maksimum dari uji kesesuaian Goodness Of Fit Test distribusi Weibull waktu Maen Time To Repair (MTTR) adalah 99 jam atau 4 hari untuk kegagalan yang tidak dapat diprediksi dengan melakukan upaya tindakan condition monitoring yaitu seperti melakukan pengecekan suhu udara diruang lobby atau remote indoor $\mathrm{AC}$, guna mengurangi terjadinya gangguan-ganguan yang mengurai kualitas kapasitas dan fasilitas Hoter Harris Yello.

\subsection{Saran}

Dalam hal ini penulisan memberikan beberapa saran yang mungkin dapat berguna untuk meningkatkan keandalan mesin. Adapun saran yang perlu dipertimbangkan adalah sebagai berikut:

1. Ketelitian tindakan pengecekan pada waktu mesin akan beroperasi perlu diperhatikan dengan mengecek komponen kritis agar kegagalan dapat diminimalisir, sehingga mesin dapat beroperasi dengan normal.

2. Sebaiknya tenaga maentenance melakukan Record Daily atau Report Split setiap 4 hari untuk menimimalisir kegagalan atau kerusakan pada mesin dan sub sistem.

\section{DAFTAR PUSTAKA}

K. Antosz, L. Pasko, and A. Gola, "to Support the to the Use of of Intelligent Intelligent Systems Systems to to Support Support Decision Systems Support Decision Lean Maintenance in Lean maintenance maintenance maintenance in maintenance maintenance," IFACPapersOnLine, vol. 52, no. 10, pp. 148 153, 2019, doi: 10.1016/j.ifacol.2019.10.037.

L. Bingchan, B. Mao, and J. Cao, "ScienceDirect and Management of Marine and of Communication Navigation Equipment Based on Virtual Reality Maintenance and Management of Marine Communication and Jie Virtual Equipment Based Reality," Procedia Comput. Sci., vol. 139, pp. 221-226, 2018, doi: 10.1016/j.procs.2018.10.254.

L. Fumagalli et al., "ScienceDirect of preventive maintenance interventions," IFAC-PapersOnLine, vol. 50, no. 1, pp. 13976-13981, 2017, doi: 10.1016/j.ifacol.2017.08.2417.

L. M. D. F. Ferreira, I. Maganha, V. S. M. Magalhães, and M. Almeida, "ScienceDirect Multicriteria Decision 
Framework for the Multicriteria Decision Framework for the Multicriteria Decision Framework for the Multicriteria Decision Framework for the Management of Maintenance Spares A Multicriteria Decision Framework for the S," IFACPapersOnLine, vol. 51, no. 11, pp. 531537, 2018 , doi: 10.1016/j.ifacol.2018.08.373.

M. A. L. Campos, L. Fumagalli, J. F. G. Fernández, A. C. Márquez, and $\mathrm{M}$. Macchi, "UML model for integration between RCM and CBM in an eMaintenance architecture," 2006, doi: 10.3182/20100701-2-PT-4012.00020.

M. Joyce et al., "at a at a Maintenance Dates at at a Maintenance Maintenance Centre in passenger," IFAC Pap., vol. 52, no. 13, pp. 957-962, doi: 10.1016/j.ifacol.2019.11.318.

M. Processes et al., "Systems for for Manufacturing Cost Oriented Maintenance Management Systems for Manufacturing Processes . and thesis," IFAC-PapersOnLine, vol. 51, no. 30, pp. 48-53, 2018, doi: 10.1016/j.ifacol.2018.11.244.

O. Yavuz, E. Doğan, E. Carus, and A.

Görgülü, "ScienceDirect ScienceDirect ScienceDirect Reliability Centered Maintenance Practices in Food Industry Reliability Centered Maintenance Practices in Food Industry," Procedia Comput. Sci., vol. 158, pp. 227-234, 2019, doi: 10.1016/j.procs.2019.09.046

Syahabuddin, A. (2019). ANALISIS PERAWATAN MESIN BUBUT CYL1640G DENGAN METODE RELIABILITY CENTERED MAINTENANCE (RCM) DI PT. POLYMINDO PERMATA. JITMI (Jurnal Ilmiah Teknik dan Manajemen Industri), 2(1), 27-36. 